\title{
VOCABULARY OF EMOTIONS IN HAGIOGRAPHIES FOR CHILDREN: FUNCTIONAL ASPECT
}

\author{
Evgeniya G. Dmitrieva \\ Volgograd State University, Volgograd, Russia
}

\begin{abstract}
The article is devoted to the problem of linguistic originality of hagiographic texts for children regarded as a special branch of hagiographic genre, which communicates to the new generation culturally significant senses and values of the ethnic group, with the emphasis on the concept of a religious and moral ideal. The source of the language material was collections of hagiographies for children. The author focuses on lexical units that nominate and describe emotional experiences. The features determining the use of units of this lexical set for the creation of texts that consider children's reading experience are established. It is shown that the specificity of using the vocabulary of emotions in a hagiographic text is determined by its functional load: its usage as a means of characterization (characterological function), the basics of compositional text formation (text-building function), the implementation of the educational orientation of the hagiographic text (didactic function). The vocabulary of emotions is an important means of creating imagery based on metaphorical and metonymic shifts, which contributes to the adaptation of the text to the age and cultural demands of the children's readership. The consideration of functional and stylistic originality of lexemes, their heterogeneity, mixing of bookish and colloquial words has enabled the author to trace transformation processes in hagiographic genre, which are characteristic of modern hagiographic texts.

Key words: hagiographies for children, vocabulary of emotions, characterological function, text-building function, didactic function, adaptation.

Citation. Dmitrieva E.G. Vocabulary of Emotions in Hagiographies for Children: Functional Aspect. Vestnik Volgogradskogo gosudarstvennogo universiteta. Seriya 2. Yazykoznanie [Science Journal of Volgograd State University. Linguistics], 2021, vol. 20, no. 6, pp. 56-64. (in Russian). DOI: https://doi.org/10.15688/jvolsu2.2021.6.5
\end{abstract}

\section{ЛЕКСИКА ЭМОЦИЙ В ЖИТИЯХ СВЯТЫХ ДЛЯ ДЕТЕЙ: ФУНКЦИОНАЛЬНЫЙ АСПЕКТ}

\author{
Евгения Геннадьевна Дмитриева \\ Волгоградский государственный университет, г. Волгоград, Россия
}

\begin{abstract}
Аннотация. Статья посвящена проблеме языкового своеобразия агиографических текстов для детей, формирующих особое направление развития житийного жанра, транслирующего для нового поколения культурно значимые смыслы и ценностные ориентиры этноса, центральным из которых является понятие религиозно-нравственного идеала. Источником языкового материала послужили сборники житий для детей. В центре внимания автора находятся лексические единицы, называющие и описывающие эмоциональные переживания. Установлены особенности, определяющие употребление единиц данного лексического множества для создания текстов, ориентированных на детский читательский опыт. Показано, что специфика ґе лексики эмоций в агиографическом тексте задается ее функциональной нагрузкой: использованием как средства характеристики (характерологическая функция), как основы композиционного построения текста (текстообразующая функция), как реализации просветительской направленности житийного текста (дидактическая функция). Лексика эмоций является важным средством создания образности на основе метафори() ческих и метонимических переносов, что способствует адаптации текста к возрастным и культурным по-
\end{abstract}


требностям детской читательской аудитории. Учет функционально-стилевого своеобразия лексем позволил увидеть в их неоднородности, смешении книжных и разговорных, просторечных слов отражение процессов трансформации житийного жанра, свойственных современным агиографическим текстам.

Ключевые слова: жития для детей, лексика эмоций, характерологическая функция, текстообразующая функция, дидактическая функция, адаптация.

Цитирование. Дмитриева Е. Г. Лексика эмоций в житиях святых для детей: функциональный аспект // Вестник Волгоградского государственного университета. Серия 2, Языкознание. - 2021 . - Т. 20, № 6. C. 56-64. - DOI: https://doi.org/10.15688/jvolsu2.2021.6.5

\section{Введение}

Изучение агиографических произведений для детей как отдельного, обширного пласта детской литературы представляет значительный интерес, поскольку позволяет проследить эволюцию житийного жанра на отечественной почве, тенденции развития языка и стиля русской агиографии в целом, механизмы творческой адаптации житийного материала, обусловленной учетом возрастных особенностей восприятия и потребностей читателя.

Ученые-литературоведы обращают внимание на неоднородность современных агиографических произведений для детей в жанровом отношении и связывают ее с перерывом в агиографической традиции, усилением авторского начала, ориентацией на современного читателя и его культурный опыт.

Поскольку жития для детей предназначены для особой аудитории, встает вопрос: являются ли эти произведения адаптированными текстами? При этом под адаптированным текстом понимается «вторичный текст, созданный для читателей, которые по какимто причинам не могут понять текст-источник» [Первухина, 2014, с. 98]. Отмечая, что трансформирование оригинального текста во вторичный вариант - это путь компрессии и адаптирования, А.В. Брыгина противопоставляет эти типы преобразований по целевому назначению: цель текстовой компрессии - «кратко изложить основное содержание, основную идею текста-оригинала» [Брыгина, 2005, с. 4]; адаптации - «донести до читателя максимум информации, заложенной в оригинальном тексте, которую он способен воспринять» [Брыгина, 2005, с. 4].

Наличие определенного прототипа - первичного текста, или прототекста, - исследователи называют одним из важнейших качеств вторичного текста [Ионова, 2006, с. 69].
Применительно к житиям для детей таких прототекстов может быть несколько: жизнеописанию одного святого часто посвящен ряд текстов, не только отличающихся степенью подробности описания, но и подчас противоречащих друг другу в отдельных деталях.

Опираясь на связи современных агиографических произведений для детей с прототекстами, Е.К. Макаренко предложила типологию, выделив: жития, восходящие к четьиминейной традиции; жития, ориентированные на проложную традицию; жития, строящиеся на основе традиций патерика и позднего Пролога; жития, соотносящиеся со светскими жанрами мемуарной и биографической прозы; жития, построенные как «текст в тексте» (назидательный рассказ с вымышленной сюжетной канвой, в которую вставлена история жизни святого) [Макаренко, 2015, с. 159-163].

Таким образом, жития для детей представляют собой интереснейший материал для филологического анализа, и если их литературоведческие характеристики нашли отражение в работах исследователей, то особенности функционирования языковых единиц в данных текстах еще не становились предметом специального рассмотрения.

\section{Материал и методы}

В качестве источника языкового материала были использованы сборники житий для детей, построенные по принципу Четий миней и объединяющие повествования о наиболее почитаемых византийских и русских подвижниках веры: «Жития святых для детей», составленные протоиреем Виктором Ильенко (книга включает избранные жития, которые впервые публиковались отдельными выпусками в 1950-1960-е гг. в Лос-Анджелесе), и «Святцы для детей. Избранные жития святых» Т. Коршуновой и М. Тряпкиной (2017). 


\section{РАЗВИТИЕ И ФУНКЦИОНИРОВАНИЕ РУССКОГО ЯЗЫКА}

Названия книг указывают как на жанровую природу текстов, так и на их предполагаемого адресата.

В центре нашего внимания находится лексика эмоций, понимаемая как совокупность лексем, служащих для обозначения и описания эмоций и чувств и их внешних проявлений. Реконструкция семантической структуры единиц, входящих в данное лексическое множество, позволила выделить их значимые семантические признаки, к которым прежде всего относятся 'эмоциональное переживание' (маркер принадлежности к группе эмотивов), 'характер эмоции' (положительная / отрицательная / нейтральная), 'интенсивность эмоционального переживания' (высокая / средняя / низкая) [Горбань и др., 2015, с. 188], 'оценка эмоционального переживания' (поощряемое / непоощряемое / амбивалентное).

Названные семантические признаки могут быть выделены в семантике любого члена данного множества и играют существенную роль при выборе той или иной лексемы автором жития.

Исследование нацелено на выявление функций, реализующихся лексикой эмоций (см. подробнее: [Дмитриева, 2020]) как средством передачи представлений о культурно значимых ценностях, и проведено с опорой на положения комплексного подхода, сформулированные в трудах С.П. Лопушанской: языковой факт рассматривается с учетом совокупности системных и функциональных, парадигматических и синтагматических характеристик слова, взаимосвязи языка и мышления [Лопушанская, 1987; 1996; 1998]. В качестве основных в работе использованы методы компонентного, контекстуального и лингвокультурного анализа.

\section{Результаты и обсуждение}

\section{Дидактическая функция лексики эмоций}

В центре внимания автора любого жития лежит представление о религиознонравственном идеале (подробнее о термине см.: [Дмитриева, 2018, с. 66]), воплощением которого и является подвижник. С этим связана особая дидактическая направленность агиографического текста. Воспринимая этот идеал, ребенок приобщается к культурным ценностям и традициям своего народа, определяющим национально-культурную идентичность. Сложность задачи, которая решается создателем агиографического текста для детей, состоит в том, чтобы объяснить маленькому читателю суть таких сложных понятий, как нравственный идеал и святость, на примере конкретных поступков, достойных подражания. Воспитательная направленность детской житийной литературы обеспечивается тем, что следование указанным образцам подается как норма жизни. При этом особое внимание уделяется созданию атмосферы личной причастности ребенка открывающемуся перед ним новому миру:

(1) Все святые были когда-то простыми людьми. И жили они, как и мы, на земле (СД, с. 7);

(2) Святые могут стать нам настоящими друзьями (СД, с. 8).

Важное место при характеристике святых уделяется эмоциональному плану:

(3) Святые тоже ошибались и даже грешили. Но обязательно каялись и очень старались очистить душу. Не унывали и просили Бога помочь исправиться. И как самое большое богатство взращивали в своей душе любовь (СД, с. 7).

В приведенном контексте лексемы унывать «впадать в безнадежную печаль, гнетущую скуку» (ТСРЯ, с. 1029) и любовь «чувство глубокого расположения, самоотверженной и искренней привязанности» (ТСРЯ, с. 421) указывают спасительный путь.

Лексика эмоций, реализуя дидактическую функцию, играет важную роль в приобщении ребенка к открывающемуся перед ним новому миру, формирует необходимые модели поведения и закрепляет ценностные ориентиры.

\section{Характерологическая функция лексики эмоций}

Обращение к описанию чувств позволяет автору сделать образ подвижника ближе и понятнее маленьким читателям. Значимыми при выборе лексем оказываются характер эмоции (положительная / отрицательная / ней- 
тральная), оценка эмоционального переживания (поощряемое / непоощряемое / амбивалентное) и «статус» описываемого лица (святой / не святой).

Абстрактные значения, присущие лексике эмоций, не всегда понятны детям. Возможно, этим фактом объясняется использование метафорических и метонимических переносов. Так, метафорическое описание чувств может строиться на их сравнении с огнем:

(4) Услыхав эти слова, князь Александр разгорелся сердцем (ЖСД, с. 79).

В приведенном контексте описывается эмоциональная реакция святого на слова захватчика, бросившего ему вызов. Глагол разгореть$c я$, то есть «начать сильно гореть» (ТСРЯ, c. 793), где гореть «испытывать какое-н. сильное чувство; существовать, проявляться (о таком чувстве)» (ТСРЯ, с. 162), употреблен в переносном значении и на конкретное чувство не указывает. Более определенные указания на чувства находим в следующих контекстах:

(5) Варвара услаждалась сердцем и горела любовью ко Христу... (ЖСД, с. 125);

(6) Потом... еще больше разгорелась Божией любовью... (ЖСД, с. 125);

(7) Постепенно в ее сердце разгорелся огонь Божественной любви... (ЖСД, с. 123).

С огнем могут сравниваться не только положительные, но и отрицательные чувства гнев, ярость:

(8) Ехать к хану, когда тот пылал яростью, значило самому идти на смерть (ЖСД, с. 94);

Эмоциональные переживания могут уподобляться вкусовым ощущениям: глаголы услаждаться и насладиться (наслаждаться) имеют значение «испытать высшую степень удовольствия» (ТСРЯ, с. 494) и этимологически связаны с прилагательным сладкий:

(9) Услышав все это, Варвара услаждалась сердщем... (ЖСД, с. 125);

(10) И тогда они слышат там слово Златоуста: «Аще кто благочестив и боголюбив, да насладится сего доброго и светлого торжества!» (ЖСД, с. 49).
В работе Анны А. Зализняк наслаждение связывается с понятием удовольствия, что следует из словарного толкования: наслаждение обусловлено непосредственным впечатлением, которое почти не имеет в своей основе рациональной оценки, и, в отличие от удовольствия, относится к области высокого. Резюмируя, ученый пишет: «...во всех типах употребления глагол наслаждаться, как и существительное наслаждение, обозначает сильное (а иногда также “высокое", то есть так или иначе не совсем “приличное”) чувство» [Зализняк, 2005, с. 174].

В православной традиции чувственная сфера связывается с сердцем, его называют «центральным органом чувств» [Святитель Лука, 1999, с. 33]. Метонимическая замена, когда сердце выступает номинацией человека, широко распространена в анализируемых текстах. Описание происходящего с сердцем призвано донести до читателя эмоциональные переживания человека. Так, особое внимание обращается на физическое состояние - биение, боль, сжатие сердца:

(11) Евфимия с благоговением взирала на святых, сердце ее трепетно билось (ЖСД, с. 72).

Существительное благоговение «глубочайшее почтение» (ТСРЯ, с. 47), сопровождаемое в словарях пометой «высокое», и наречие трепетно, связанное отношениями производности с прилагательным трепетный и существительным mpenem «сильное волнение, напряженность чувств» (ТСРЯ, с. 998), имеющим помету «книжное», описывают происходящее во внутреннем мире героини.

(12) Радостно забилось сердце кн. Александра при этом рассказе... (ЖСД, с. 82).

Глагол забиться, имеющий основное значение «начать биться» (ТСРЯ, с. 239), конкретизируется наречием радостно, производным от прилагательного радостный «полный радости, веселья; выражающий радость» (ТСРЯ, с. 787).

(13) Диоскор же, жестокосердый отец Варвары, не только не болел сердцем, видя великие муки своей дочери, но не постыдился стать и ее палачом (ЖСД, с. 130). 


\section{РАЗВИТИЕ И ФУНКЦИОНИРОВАНИЕ РУССКОГО ЯЗЫКА}

Глагол болеть использован в переносном значении «сильно беспокоиться, постоянно тревожиться, остро переживая что-н.» (ТСРЯ, c. 54).

(14) Больно сжалось его сердце при виде своего бывшего господина в нищенском облике (ЖСД, c. 141).

Глагол сжаться «о чем-н. сдавливаемом, сжимаемом: плотно сдвинуться, уплотниться» употреблен в переносном значении - «об ощущении тоски, страха» (ТСРЯ, с. 878), отсылающем нас к чувству жалости.

Физическое состояние сердца часто выступает основой для метафор, описывающих внутренние переживания. При этом сердце выступает:

- вместилищем для чувств:

(15) ...Святая ощутила в сердце своем неизъяснимую радость (ЖСД, с. 128);

- жидкостью, которая может кипеть (16) или застывать, а потом таять (17):

(16) София едва могла дождаться конца фразы: сердце ее кипело гневом на лжеца и клятвопреступника (ЖСД, с. 75);

(17) При этом рассказе сердце Софии таяло от жалости... (ЖСД, с. 73).

Сердце - средоточие эмоциональночувственной жизни человека, вместилище любви, тоски, веры, страха и т. д. По представлениям славян, в сердце или рядом с ним локализуется душа. Впрочем, сердце иногда противопоставляется душе. Сердце становится синонимом характера, а также метонимически означает самого человека [Агапкина, Кабакова, Топорков, 2012, с. 258-260].

В таком случае сердце само приобретает способность чувствовать, переживать эмоции:

(18) Но его сердце не озлобилось от страданий (ЖСД, с. 51); c. 66).

(19) Но материнское сердце чуяло беду (ЖСД,

Лексема озлобиться фиксируется в толковом словаре в значении «ожесточиться, стать злобным» (ТСРЯ, с. 560). Глагол чуять в зна- чении «чувствовать, ощущать» относится к просторечным лексемам (ТСРЯ, с. 1099). В случае, когда субъект действия обозначен существительным сердие, в контексте речь идет о догадке, предчувствии чего-то недоброго.

Как отмечают исследователи, центральную роль в системе внутреннего мира современного человека играет душа, для древнерусской культуры подобную функцию выполняло сердце. Это отражается в текстах и определяется наибольшей частотностью употребления соответствующего имени, а также наиболее широким спектром функций, которые оно выполняет [Колесов, Колесова, Харитонов, 2014, с. 237].

Важно отметить, что «душа, как она представлена в языке, отвечает за различные психические процессы; сердце же понимается как материальная субстанция, “платформа" для души и связанных с ней явлений» [Зибров, 2011, с. 110]

Опираясь на данные языка, Е.В. Урысон называет душу и сердце органами чувств, а также органами предчувствий, то есть «органами, с помощью которых человек может интуитивно постигать то, что произойдет в будущем, а также то, что было в прошлом или происходит в настоящий момент» [Урысон, 2003, c. 22]. Раскрывая отличия души и сердца, исследователь связывает последнее с конкретными чувствами и желаниями, но не внутренним миром в целом, а также указывает на большую независимость этих чувств и желаний от конкретных внешних обстоятельств [Урысон, 2003 , с. 24]. Сердце настолько неподвластно воле, что субъект может рассматривать его отчужденно [Урысон, 2003, с. 26].

Анализируя представления о духе, душе, сердце и уме, отраженные в древнерусских текстах XI-XII вв., А.А. Шайкин отмечает, что сердце - первое, к чему обращается Бог в составе человека; желая побудить человека к какому-либо действию, Бог «вкладывает ему в сердце»; общение с Богом в человеке главным образом осуществляет душа, однако душа утверждена в сердце, поскольку сердце - материальное вместилище души [Шайкин, 2015, с. 118-119]. Исследователь описывает сердце и душу в единстве («сердце-душа»), говоря об их общей референциальной сущности. 
Е.Г. Дмитриева. Лексика эмоций в житиях святых для детей: функциональный аспект

Рассмотренные метонимические переносы с лексемами сердие и душа показывают, насколько важным является для создателя жития эмоциональная сфера, поскольку наименование «центра чувств» становится обозначением человека, а человек характеризуется через свои эмоции.

\section{Текстообразующая функция лексики эмоций}

Выбранные нами сборники житий позволяют сделать наблюдения о разных подходах к адаптации агиографического текста, проявляющихся и в употреблении лексики эмоций. Сопоставим рассказ о святых мученицах Вере, Надежде, Любови и матери их Софии в интерпретации протоиерея Виктора Ильенко и соавторов Татьяны Коршуновой и Марии Тряпкиной.

Первое повествование более пространное. Оно следует житийному канону и содержит топосы благочестивых родителей, успехов в воспитании. В основной части главной героиней является София, сестры Вера, Надежда и Любовь получают обобщенное обозначение - дети. Автор показывает их отдельно только в заключительной части, в момент принятия мук, которые описаны очень подробно.

Особое внимание уделено описанию чувств. Ключевые действия героев всегда эмоционально окрашены и противопоставлены: при первой встрече с императором София и ее дочери спокойны, а он поражен; перед казнью София убеждает дочерей помнить о грядущих утешении и радости; во время казни девочки не боятся, а Адриан смущен, поражен, выведен из терпения.

Важное место занимает обращение Coфии к детям, ее напутствие перед судом императора. Переданное как прямая речь, оно реализует воспитательные интенции автора:

(20) Не жалейте вашей красоты! Когда она будет отнята муками, Христос украсит вас небесной красотою (ЖСД, с. 6).

Эти слова косвенно свидетельствуют о том, что дети воспринимаются автором как «маленькие взрослые». Текст жития требует от читателей серьезной внутренней работы по преодолению некоторой дистанции между современными представлениями и реалиями предшествующих эпох, по расширению культурного опыта.

Кроме того, язык произведения наполнен устаревшей, книжной лексикой, которая может затруднять восприятие текста. Обратимся к следующему контексту:

(21) София встала с детьми на молитву. Она молилась так: «Всесильный Боже, подаждь нам помощь Твою святую, да не устрашится сердце наше гордого мучителя, да не ужаснемся мук и горькой смерти за имя Твое!» (ЖСД, с. 4).

Глагол устрашиться «испугаться, почувствовать страх перед кем-чем-н.» в словарях может сопровождаться пометой «книжное» (ТСРЯ, с. 1036), глагол ужаснуться «прийти в ужас» (ТСРЯ, с. 1021) фиксируется как стилистически нейтральный. Однако глагол устрашиться, употребленный в прямом значении, предполагает наличие конкретного, одушевленного субъекта, в приведенном контексте субъект выражен существительным сердие. Обращает на себя внимание и архаичная глагольная форма подаждь. Стоит отметить, что книжные, устаревшие лексемы чаще встречаются в речи героев, являясь своеобразным художественным приемом создания речевой характеристики.

В целом можно говорить о реализованном автором стремлении остаться в рамках житийной традиции.

Второе изложение больше напоминает рассказ о жизни трех девочек, который, несмотря на краткость, содержит дополнительные детали: например, мы узнаем об их отце, который был язычником, но «разрешал любимой жене воспитывать дочек в христианской вере» (СД, с. 134); о том, чему посвящали будущие святые свое время:

(22) ...Они любили трудиться и помогать своей матери; любили молиться и читать Священное Писание (СД, с. 134).

Упоминают авторы и о том, что может быть дорого современным детям:

(23) Ни платьев нарядных, ни игрушек излишних, ни сладостей у девочек не было. Да им все это было неинтересно... (СД, 134). 
Последний фрагмент подтверждает дидактическую направленность второго текста, авторы которого показывают, что подвиг, совершенный юными христианками, был подготовлен их праведной жизнью. Простота уклада семейного быта Софии противостоит пышности и богатству дворцовых покоев. В композиционном плане благочестивая семья противопоставлена не только императору Андриану, но и завистникам, недоброжелателям, которые «нажаловались» правителю.

Данная антитеза поддерживается и в эмоциональном плане: жизнь святых мучениц наполнена любовью, радостью, воодушевлением, но им знакома и скорбь, их антагонисты завидуют, гневаются, чувствуют собственное бессилие. При этом лексемы, обозначающие переживания героев, общеупотребительны и стилистически нейтральны.

Таким образом, лексика эмоций играет важную роль в построении текста: организует его композиционную структуру, эксплицирует интенции автора, делает текст доступным потенциальному читателю.

\section{Выводы}

Обращение к анализу современных житий для детей показало, что лексика эмоций выступает важным средством создания образов подвижников как воплощения нравственного идеала, организует повествование, peaлизуя характерологическую, текстообразующую и дидактическую функции.

В рассмотренных текстах описания чувств наполнены образностью и строятся на принципах метафоры и метонимии; сохраняются традиционные сравнения чувств человека с огнем; в метонимических переносах частотны лексемы сердие и душа.

В функционально-стилевом отношении лексика эмоций, употребленная в проанализированных житиях, неоднородна: встречаются слова книжные, устаревшие и просторечные. Это обусловлено противоречивыми процессами развития жанра жития: с одной стороны, размывание его границ, влияние художественного, публицистического и даже официально-делового стилей, а с другой - консерватизм, стремление сохранить традицию житийного канона.
В следовании одной из этих тенденций проявляется творческая установка автора жития, в конечном итоге определяющая его взгляд на адаптацию текста к возможностям восприятия и понимания юными читателями.

\section{СПИСОК ЛИТЕРАТУРЫ}

Агапкина Т. А., Кабакова Г. И., Топорков А. С., 2012. Сердце // Славянские древности : Этнолингвистический словарь. В 5 т. Т. 5 / под общ. ред. Н. И. Толстого. М. : Междунар. отношения. C. 258-262.

Брыгина А. В., 2005. Лингвистические принципы адаптирования художественного текста : автореф. дис. ... канд. филол. наук. М. 15 с.

Горбань О. А., Дмитриева Е. Г., Косова М. В., Сафонова И. А., Терентьева Е. В., Шептухина Е. М., 2015. Семантика древнерусского глагола: синхронно-диахронический аспект. 2-е изд., доп. М. : Флинта : Наука. 352 с.

Дмитриева Е. Г., 2018. Религиозно-нравственный идеал в современных агиографических текстах: лингвистическая характеристика // Научный диалог. № 12. С. 64-74. DOI: 10.24224/ 2227-1295-2018-12-64-74.

Дмитриева Е. Г., 2020. Функции эмотивной лексики как средства реализации религиозно-нравственного идеала в житийных текстах XVIIIXX веков // Acta Universitatis Lodziensis. Folia Linguistica Rossica. № 19. C. 41-52. DOI: https:// doi.org/10.18778/1731-8025.19.04.

Зализняк Анна А., 2005. Счастье и наслаждение в русской языковой картине мира // Ключевые идеи русской языковой картины мира : сб. ст. М. : Яз. слав. культуры. С. 153-174.

Зибров Д. А., 2011. Сердце // Антология концептов / под ред. В. И. Карасика, И. А. Стернина. Волгоград : Парадигма. Т. 8. С. 104-114.

Ионова С. В., 2006. О двух моделях построения вторичных текстов // Вестник Волгоградского государственного университета. Серия 2 , Языкознание. Вып. 5. С. 69-76.

Колесов В. В., Колесова Д. В., Харитонов А. А., 2014. Словарь русской ментальности. В 2 т. Т. 2. СПб. : Златоуст. 592 с.

Лопушанская С. П., 1987. Парадигматические и синтагматические отношения древнерусских бесприставочных глаголов движения // Русский глагол в сопоставительном освещении. Парадигматические и синтагматические отношения : межвуз. науч. сб. Саратов : Изд-во Сарат. ун-та. С. 3-12.

Лопушанская С. П., 1996. Семантическая модуляция как речемыслительный процесс // Вестник 
Волгоградского государственного университета. Серия 2, Филология. Вып. 1. С. 6-13.

Лопушанская С. П., 1998. Конкретно-пространственное и абстрактно-пространственное восприятие мира человеком как философская основа объяснения эволюции языка // Человек в современных философских концепциях : материалы Междунар. науч. конф. (Волгоград, 17-19 сент. 1998 г.). Волгоград : Изд-во ВолГУ. C. 337-346.

Макаренко Е. К., 2015. Жанровые модификации современный агиографических произведений для детей // Вестник ТГПУ. № 10 (163). C. $157-165$.

Первухина С. В., 2014. Виды адаптации текста // Вестник Южно-Уральского государственного университета. Серия «Лингвистика». Т. 11, № 1. С. 97-100.

Святитель Лука (Войно-Ясенецкий), 1999. Дух, душа и тело. М. : Православ. Свято-Тихон. богосл. ин-т : Рус. зерцало. 175 с.

Урысон Е. В., 2003. Проблемы исследования языковой картины мира : Аналогия в семантике. М. : Яз. слав. культуры. 224 с.

Шайкин А. А., 2015. Дух, душа, сердце, ум в древнерусских текстах XI-XII вв. // Древняя Русь : Пространство книжного слова. Историко-филологические исследования / отв. ред. В. М. Кириллин. М. : Яз. слав. культуры. С. 108-131.

\section{ИСТОЧНИКИ}

ЖСД - Ильенко В. Жития святых для детей. М. : Артос-Медиа, 2011. 384 с.

СД - Коршунова Т., Тряпкина М. Святцы для детей. Избранные жития святых. М. : Никея, 2017. 181 с.

\section{СЛОВАРЬ}

ТСРЯ - Толковый словарь русского языка с включением сведений о происхождении слов / отв. ред. Н. Ю. Шведова. М. : Азбуковник, 2011. 1175 с.

\section{REFERENCES}

Agapkina T.A., Kabakova G.I., Toporkov A.S., 2012. Serdtse [Heart]. Tolstoy N.I., ed. Slavyanskie drevnosti: Etnolingvisticheskiy slovar. $V 5 t$. T. 5 [Slavic Antiquities. Ethnolinguistic Dictionary. In 5 Vols. Vol. 5]. Moscow, Mezhdunar. otnosheniya Publ., pp. 258-262.

Brygina A.V., 2005. Lingvisticheskie printsipy adaptirovaniya khudozhestvennogo teksta: avtoref. dis. ... kand. filol. nauk [Linguistic Principles of Adaptation of a Literary Text. Cand. philol. sci. abs. diss]. Moscow. 15 p.

Gorban O.A., Dmitrieva E.G., Kosova M.V., Safonova I.A., Terenteva E.V., Sheptukhina E.M., 2015. Semantika drevnerusskogo glagola: sinkhronno-diakhronicheskiy aspekt [Semantics of Old Russian Verb: Synchronous and Diachronic Aspect]. Moscow, Flinta Publ., Nauka Publ. 352 p.

Dmitrieva E.G., 2018. Religiozno-nravstvennyy ideal v sovremennykh agiograficheskikh tekstakh: lingvisticheskaya kharakteristika [Religious and Moral Ideal in Modern Hagiographic Texts: Linguistic Characteristics]. Nauchnyi dialog, no. 12,pp. 64-74. DOI: 10.24224/2227-1295-201812-64-74.

Dmitrieva E.G., 2020. Funktsii emotivnoy leksiki kak sredstva realizatsii religiozno-nravstvennogo ideala v zhitiynykh tekstakh XVIII-XX vekov [Functions of Emotive Vocabulary As a Means of Pursuing Religious and Moral Ideal in the Hagiographic Texts of the $18^{\text {th }}-20^{\text {th }}$ Centuries]. Acta Universitatis Lodziensis. Folia Linguistica Rossica, no. 19, pp. 41-52. DOI: https://doi.org/ 10.18778/1731-8025.19.04.

Zaliznyak Anna A., 2005. Shchastye i naslazhdenie v russkoy yazykovoy kartine mira [Happiness and Pleasure in the Russian Language Picture of the World]. Klyuchevye idei russkoy yazykovoy kartiny mira: sb. st. [Key Ideas of the Russian Language Picture of the World. Collection ofArticles]. Moscow, Yazyki slavyanskoykultury Publ., pp. 153-174.

Zibrov D.A., 2011. Serdtse [Heart]. Karasik V.I., Sternin I.A., eds. Antologiya kontseptov [Anthology of Concepts]. Volgograd, Paradigma Publ., vol. 8, pp. 104-114.

Ionova S.V., 2006. O dvukh modelyakh postroeniya vtorichnykh tekstov [On Two Models of Construction of Secondary Texts]. Vestnik Volgogradskogo gosudarstvennogo universiteta. Seriya 2, Yazykoznanie, iss. 5, pp. 69-76.

Kolesov V.V., Kolesova D.V., Kharitonov A.A., 2014. Slovar russkoy mentalnosti. V 2 t. T. 2 [Dictionary of Russian Mentality. In 2 Vols. Vol. 2]. Saint Petersburg, Zlatoust Publ. 592 p.

Lopushanskaya S.P., 1987. Paradigmaticheskie i sintagmaticheskie otnosheniya drevnerusskikh bespristavochnykh glagolov dvizheniya [Paradigmatic and Syntagmatic Relations of Old Russian Non-Prepositional Verbs of Movement]. Russkiy glagol v sopostavitelnom osveshchenii. Paradigmaticheskie i sintagmaticheskie otnosheniya: mezhvuz. nauch. sb. [The Russian Verb in Comparative Perspective. Paradigmatic and Syntagmatic Relations. Interuniversity 


\section{РАЗВИТИЕ И ФУНКЦИОНИРОВАНИЕ РУССКОГО ЯЗЫКА}

Collection of Scientific Papers]. Saratov, Izd-vo Sarat. un-ta, pp. 3-12.

Lopushanskaya S.P., 1996. Semanticheskaya modulyatsiya kak rechemyslitelnyy protsess [Semantic Modulation As a Verbal and Cogitative Process]. Vestnik Volgogradskogo gosudarstvennogo universiteta. Seriya 2, Filologiya, iss. 1, pp. 6-13.

Lopushanskaya S.P., 1998. Konkretno-prostranstvennoe i abstraktno-prostranstvennoe vospriyatie mira chelovekom kak filosofskaya osnova obyasneniya evolyutsii yazyka [ConcreteSpatial and Abstract-Spatial Human Perception of the World As the Philosophical Basis for Explaining the Evolution of Language]. Chelovek $v$ sovremennykh filosofskikh kontsepciyakh: materialy Mezhdunar. nauch. konf. (Volgograd, 17-19 sent. 1998 g.) [Human in Modern Philosophical Concepts. Proceedings of the International Scientific Conference (Volgograd, September 17-19, 1998)]. Volgograd, Izd-vo VolGU,pp. 337-346.

Makarenko E.K., 2015. Zhanrovye modifikatsii sovremennykh agiograficheskikh proizvedeniy dlya detey [Genre Modifications of Modern Hagiographic Works for Children]. Vestnik TGPU [Science Journal of TSPU], no. 10 (163), pp. 157-165.

Pervukhina S.V., 2014. Vidy adaptatsii teksta [Types of Text Adaptation]. Vestnik YuzhnoUralskogo gosudarstvennogo universiteta. Seriya «Lingvistika» [Bulletin of the South Ural State University. Linguistics], vol. 11, no. 1, pp. 97-100.

Svyatitel Luka (Voyno-Yasenetskiy), 1999. Dukh, dusha $i$ telo [Spirit, Soul and Body]. Moscow,
Pravoslavnyy Svyato-Tikhonovskiy bogoslovskiy institut; Russkoe zertsalo Publ. 175 p.

Uryson E.V., 2003. Problemy issledovaniya yazykovoy kartiny mira: Analogiya v semantike [Problems of Studying the Linguistic Picture of the World: Analogy in Semantics]. Moscow, Yazyki slavyanskoy kultury Publ. 224 p.

Shaykin A.A., 2015. Dukh, dusha, serdtse, um v drevnerusskikh tekstah XI-XII vv. [Spirit, Soul, Heart, Mind in Ancient Russian Texts of the $11^{\text {th }}-12^{\text {th }}$ Centuries]. Kirillin V.M., ed. Drevnyaya Rus: Prostranstvo knizhnogo slova. Istorikofilologicheskie issledovaniya [Ancient Russia: The Space of a Book Word. Historical and Philological Research]. Moscow, Yazyki slavyanskoy kultury Publ., pp. 108-131.

\section{SOURCES}

Ilyenko V. Zhitiya svyatykh dlya detey [Hagiographies of Saints for Children]. Moscow, Artos-Media Publ., 2011.384 p.

Korshunova T., Tryapkina M. Svyattsy dlya detey. Izbrannye zhitiya svyatykh [Church Calendars for Children. Selected Hagiographies of Saints]. Moscow, Nikeya Publ., 2017. 181 p.

\section{DICTIONARY}

Shvedova N.Yu., ed. Tolkovyy slovar russkogo yazyka $s$ vklyucheniem svedeniy o proishozhdenii slov [Explanatory Dictionary of the Russian Language with Information on the Origin of Words]. Moscow, Azbukovnik Publ., 2011. 1175 p.

\section{Information About the Author}

Evgeniya G. Dmitrieva, Candidate of Sciences (Philology), Associate Professor, Head of the Department of Russian Philology and Journalism, Volgograd State University, Prosp. Universitetsky, 100, 400062 Volgograd, Russia, eg_dmitrieva@volsu.ru, iryas@volsu.ru, https://orcid.org/0000-0001-5117-5677

\section{Информация об авторе}

Евгения Геннадьевна Дмитриева, кандидат филологических наук, доцент, заведующая кафедрой русской филологии и журналистики, Волгоградский государственный университет, просп. Университетский, 100, 400062 г. Волгоград, Россия, eg_dmitrieva@volsu.ru, iryas@volsu.ru, https://orcid.org/0000-0001-5117-5677 